\title{
EVALUATION OF THE ANTIMICROBIAL EFFECT OF COCONUT AND NIGELLA SATIVA OILS ON STREPTOCOCCOUS MUTANS, LACTOBACILLI AND CANDIDA ALBICANS. AN INVITRO-STUDY
}

\author{
Manal A. El-Sayed*, Norhan A. El-Dokky* and Somaia A.Eissa**
}

\begin{abstract}
Back to nature is the concept that most of workers in the medical and dental fields are searching for nowadays. Coconut oil and Nigella sativa are used to treat a wide range of health problems. In the dental field they had been documented to possess an inhibitory effect on some oral cariogenic microorganisms. Aim: Thus, the aim of the current study was to evaluate the antibacterial effect of Coconut and Nigella Sativa oils on Streptococcus mutans, Lactobacilli and Candida albicans as a natural mean for prophylaxis against dental caries.
\end{abstract}

Materials and methods: Two herbal oils (Coconut and Nigella sativa) and Chlorhexidine gluconate $0.2 \%$ as a positive control were used in this study. Streptococcus mutans, Lactobacilli, and Candida albicans were isolated and incubated. Growth inhibitory effect of the tested materials was evaluated by direct contact method for each microorganism separately by adding $0.5 \mathrm{ml}$. of the tested material to each organism in a sterile tube and incubated at $37^{\circ} \mathrm{C}$ aerobically for Streptococcus mutans and Candida albicans and anaerobically for Lactobacilli then the tested microorganisms were spread on specific media. The count of the microorganisms was expressed as CFU/plate and recorded after 2 and 24 hours.

Results: Coconut oil showed marked \% of reduction on both SM and Candida albiacans $(89.3 \%$ and $87.3 \%)$ after 24 hours contact period. Nigella Sativa oil showed marked reduction on SM after 2 hours only (68.33\%) with no effect on Candida albicans. Both oils had no effect on LB. The highest $\%$ of reduction of all tested microorganisms was recorded with Chlorhexidine.

Conclusions: Coconut oil has a great inhibitory effect on both SM and Candida albicans with this effect extending by time, but no effect on LB. Nigella sativa oil has an inhibitory effect on SM over a short contact period, but this effect decreased and even vanished by time, but it has no effect on neither Candida albicans nor LB. Chlorhexidine showed the most superior results on all tested microorganisms.

KEYWORDS: Antimicrobial agents, dental caries, Nigella sativa, Coconut oil, Streptococcus mutans, Lactobacilli, Candida albicans.

\footnotetext{
* Associate Professor of Pediatric Dentistry- Faculty of Dentistry - Cairo University

** Professor of Immunology \& Microbiology- Faculty of Medicine- Cairo University
} 


\section{INTRODUCTION}

Dental caries is one of the most common oral diseases among children (1),in many countries there is decrease in the prevalence of dental caries in children over the past years, however, in other developing countries prevalence of caries has increased ${ }^{(2)}$.

Micro-organisms present in dental plaque accumulated on tooth surface have a major role in development of dental caries $^{(3)}$, Streptococcus mutans (SM), Lactobacilli (LB) and Candida albicans are the predominant cariogenic micro-organisms associated with carious lesions ${ }^{(4)}$. The prevention strategy of dental caries mainly involves approaches to reduce the microbial load ${ }^{(5)}$.

Several antimicrobial agents have been introduced aiming of suppressing the cariogenic micro-organisms ${ }^{(6)}$.

Chlorhexidine (Chx) is the gold standard as it possesses wide antimicrobial activity, so it can inhibit cariogenic micro-organisms ${ }^{(7)}$, however, it may cause brown staining of teeth and resin restorations ${ }^{(8)}$, and hence the use of herbal agents can be a useful alternative ${ }^{(9)}$.

Herbal products have been used since ancient times in folk medicine ${ }^{(10)}$, medicinal plants are utilized in the preparation of herbal medicines as they are safer in comparison to recent allopathic drugs ${ }^{(11)}$.

One of the most important medicinal plants is Nigella sativa, commonly known as black seed, it has rich historical and religious background, it is emerging as miracle herb since many studies revealed its wide range of pharmacological activity ${ }^{(12)}$.

Several studies have reported many biological activities of Nigella sativa including: anticancer, anti-inflammatory, antioxidant and antimicrobial, some studies revealed that these properties are due to the presence large amount of thymoquinone, the major bioactive component of the essential oils ${ }^{(13,14)}$.

In a study carried out to assess the anticariogenic potency of Nigella sativa essential oil, it revealed that the oil was not only found to have a bactericidal activity against Streptococcus mutans but also inhibit the adherence of Streptococcus mutans to the surface of the teeth ${ }^{(15)}$.

Another research was conducted using agar diffusion test followed by a minimum bactericidal concentration (MBC) determination to test the Nigella sativa oil extract's sensitivity to Streptococcus mutans and its potency to inhibit bacterial adherence to the dental plaque compared with chlorhexidine gluconate, the results showed that the extract has a bactericidal effect against Streptococcus mutans at a concentration of $10 \%$ and can inhibit the adherence of these microorganisms to tooth surface ${ }^{(16)}$.

Further study evaluated the effect of 2 different extracts of Nigella sativa against cariogenic bacteria, the results showed that methanolic extract of Nigella sativa has stronger effect than ether extract ${ }^{(17)}$.

Recently, a study carried out to evaluate the antimicrobial activity of oil in water emulsion of Nigella sativa oil extract against dental cariogenic bacteria, the results concluded that the emulsion of oil extract possesses antimicrobial activity against tested bacteria ${ }^{(18)}$.

Coconut oil is another widely used edible oil, it is a unique source of natural products, due to its high content of medium chain fatty acids. It is composed of $92 \%$ saturated acids, with Lauric acid being the main component which possesses antimicrobial, antioxidant, and anti-inflammatory properties ${ }^{(19,20)}$.

In a study testing the antimicrobial properties of coconut on organisms collected from carious cavities of affected teeth, the results revealed that it has significant inhibitory effect against oral pathogens due to active effective ingredients ${ }^{(5)}$. 
Another in vivo study comparing the antibacterial efficacy of Coconut oil and Chlorhexidine on Streptococcus mutans, concluded that Coconut oil has the same effect as Chlorhexidine on $\mathrm{SM}^{(21)}$.

Recently, comparing the antifungal activity of coconut oil to known antifungal agents revealed that coconut oil and chlorhexidine have shown significant antifungal activity comparable to ketoconazole ${ }^{(22)}$.

This study aimed to evaluate the possible antibacterial effect of Nigella sativa and Coconut oils in comparison to Chlorhexidine against Streptococcus mutans, Lactobacilli and Candida albicans for prophylaxis against dental caries.

\section{MATERIALS AND METHODS}

Materials: Three test materials, two of them were of herbal (plant) origin: Coconut and Nigella Sativa oils (Nile Company for volatile \& non-volatile oils) and the third was Chlorhexidine gluconate $0.2 \%$ as a positive control were used in this study to evaluate their inhibitory effect against three types of cariogenic microorganisms ( Streptococcus mutans, Lactobacilli and Candida albicans).

The study was conducted in accordance with the ethical guidelines in research with human participants and approved by the Ethics Committee of Faculty of Dentistry, Cairo University. These ethical guidelines are in accordance with the World Medical Association Declaration of Helsinki.

\section{Saliva samples and cariogenic microorganisms}

Saliva samples were collected from children attending the Pediatric Dentistry Department, Faculty of Dentistry, Cairo University. Those children were diagnosed as having high caries index. These samples were collected early in the morning before breakfast and before tooth brushing ${ }^{(23)}$. From these samples the following micro-organisms were isolated:
a) Streptococcus mutans (SM).
b) Lactobacilli (LB).
c) Candida albicans.

All microbiological tests were conducted in the Immunology and Microbiology Department, Faculty of Medicine, Cairo University.

Methods:

\section{Isolation of microbial strains:}

a) Mitis Salivarius agar plates for isolation of Streptococcus mutans (SM) were used and incubated in a candle jar for 48 hours at $37^{\circ} \mathrm{C}$.

b) Blood agar plates for isolation of Lactobacilli (LB) were used and incubated in anaerobic jar for 72 hours at $37^{\circ} \mathrm{C}$.

c) Sabaro dextrose plates containing chloramphenicol to inhibit bacterial growth for isolation of Candida albicans and incubated aerobically for 48 hours at $37^{\circ} \mathrm{C}$.

After the incubation period, all plates were examined, and each organism was identified by colony morphology, gram stain and biological reactions if needed.

\section{Preparation of microorganisms:}

Each organism was prepared into a suspension using sterile broth and turbidity was adjusted at McFarland 0.5 which equals to:

- $\mathrm{SM}=1 \times 10^{7} \mathrm{CFU} / \mathrm{ml}$.

- $\mathrm{LB}=1 \times 10^{7} \mathrm{CFU} / \mathrm{ml}$.

- $\quad$ Candida albicans $=1 \times 10^{5} \mathrm{CFU} / \mathrm{ml}^{(24)}$.

After isolation of these organisms, they were incubated separately in the proper atmosphere to obtain the control plates as a base line data.

\section{Test for inhibition:}

Growth inhibitory effect of the test materials was evaluated by direct contact method for each microorganism separately by adding $0.5 \mathrm{ml}$. of the test material (Coconut and Nigella Sativa oils) as well as Chlorhexidine $0.2 \%$ to each organism in a sterile tube and incubated at $37^{\circ} \mathrm{C}$ aerobically for 
Streptococcus mutans and Candida albicans and anaerobically for Lactobacilli.

- For SM $25 \mu$ were spread over the surface of blood agar and incubated again at $37^{\circ} \mathrm{C}$ for $24-$ 48 hours.

- For LB $25 \mu$ were spread over the surface of blood agar and incubated at $37^{\circ} \mathrm{C}$ for 48 hours.

- For Candida albicans $25 \mu$ were spread over the surface of Sabaro dextrose and incubated at $37^{\circ} \mathrm{C}$ aerobically for $24-48$ hours.

- For each organism -ve control was done by following the same steps without adding the tested materials.

The microbial count was done after 2 and 24 hours contact period. The count of was expressed as $\mathrm{CFU} /$ plate. Six plates of every organism were tested and the mean number of CFU for all plates was calculated, tabulated and statistically analysed.

Percentage of reduction was calculated by the following equation:

$\%$ of reduction $=$ No of CFU/control- CFU/test No of CFU/Control $\quad \mathrm{x} 100$

\section{Statistical analysis:}

Numerical data were explored for normality by checking the data distribution, calculating the mean and median values and using Kolmogorov-Smirnov and Shapiro-Wilk tests. Data showed parametric distribution so; it was represented by mean and standard deviation (SD) values. Repeated measures ANOVA test was used to study the effect of mouth wash type, time and their interactions on mean number of CFU. Bonferroni's post-hoc test was used for pair-wise comparisons when ANOVA test is significant. One-way ANOVA test was used to compare between $\%$ of reduction of bacterial counts in the three groups.

The significance level was set at $\mathrm{P} \leq 0.05$. Statistical analysis was performed with IBM® SPSS ${ }^{\circledR}$ Statistics Version 20 for Windows.

\section{RESULTS}

This study compared the antimicrobial effect of two herbal oils (Coconut and Nigella sativa oil) versus Chlorhexidine gluconate $0.2 \%$ as gold standard on 3 types of oral cariogenic microorganisms (Streptococcus mutans, Lactobacilli and Candida albicans)

\section{Streptococcus mutans}

The results of this study showed that Coconut oil had a statistically significant higher inhibitory effect on SM with decrease in number of CFU from 500 to 40 and 53.7 and percentage of reduction $92 \%$ and $89.3 \%$ at 2 and 24 hours contact period consecutively as shown in (tables (1 \& 2) \& fig. (1)) and (fig. 2 A \& B).

Also, Nigella sativa oil showed an inhibitory effect on SM after 2 hours contact period with decrease in number of CFU from 500 to 158.3 and percentage of reduction $68.3 \%$, but it had no effect on the organisms after 24 hours contact period with zero $\%$ of reduction (table (1\& $2 \&$ fig. (1)) and (fig. $2 \mathrm{C} \& \mathrm{D})$.

\section{Lactobacilli}

Surprisingly, both tested herbal oils (Coconut and Nigella sativa oils) had no effect on LB species neither after 2 nor 24 hours contact period with zero $\%$ of reduction (table (1\& 2 \& fig. (1)).

\section{Candida albicans}

Regarding the effect of the tested herbal oils on Candida albicans the results showed that, coconut oil had a statistically significant high inhibitory effect on the organism with decrease in number of CFU from 500 to 62.3 and 63.3 and \% of reduction 87.5 and $87.3 \%$ after 2 and 24 hours contact period consecutively ( 1 \& 2) \& fig. (1)) and (fig 3 A \& B). Meanwhile Nigella sativa oil showed no effect on this organism (table $(1 \& 2)$ \& fig. (1)) and (fig. 3 C \& D) 
By comparing the antimicrobial effect of decrease in number of CFU from 500 to 2.7,2 and 2 these two herbal oils versus our gold standard Chlorhexidine gluconate $0.2 \%$ the later showed superior results on all tested microorganisms with and a \% of reduction $99.5,99.6$ and $99.6 \%$ for SM, LB, and Candida species at 2 and 24 hrs. contact period consecutively (table (1\& 2) and fig. 1).

TABLE (1) Mean, standard deviation (SD) values and results of comparison between CFU counts in the three groups and the changes within each group at different times.

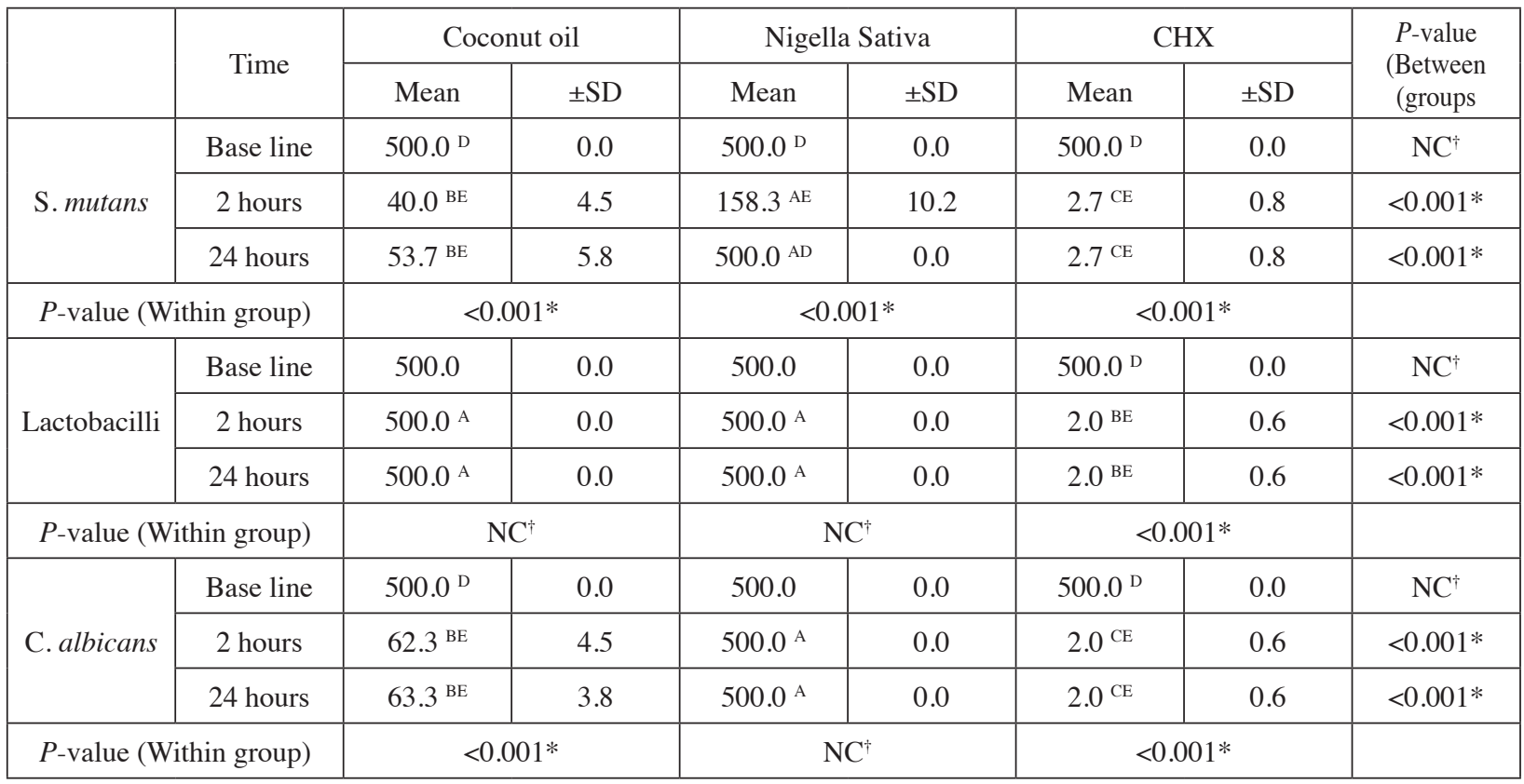

*: Significant at $P \leq 0.05, N C *$ : Not computed because $S D$ in all groups $=0$

$A, B, C$ superscripts in the same row indicate statistically significantly difference between groups

$D, E, F$ superscripts in the same column indicate statistically significantly difference between time periods

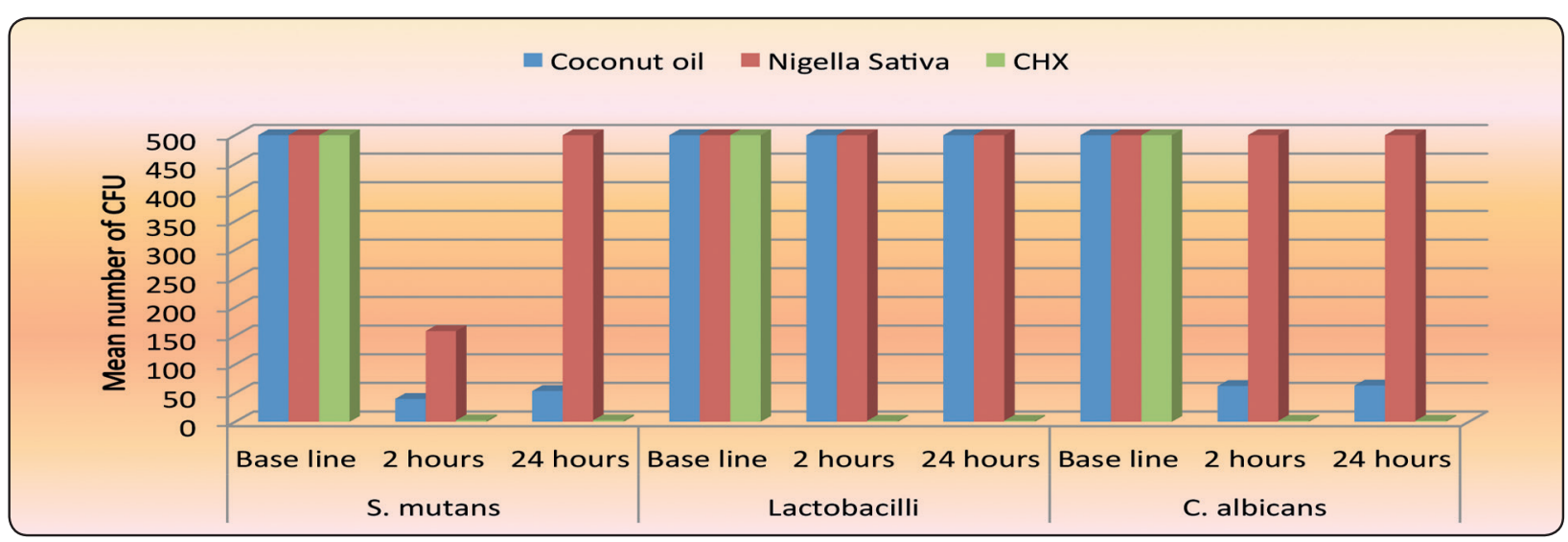

Fig. (1): Bar chart representing mean number of CFU in the three groups at different times. 
TABLE (2): Mean ,standard deviation (SD) values and results of comparison between percentage of reduction of CFU counts in the three groups.

\begin{tabular}{|c|c|c|c|c|c|c|c|c|}
\hline & \multirow[b]{2}{*}{ Time } & \multicolumn{2}{|c|}{ Coconut oil } & \multicolumn{2}{|c|}{ Nigella Sativa } & \multicolumn{2}{|c|}{$\mathrm{CHX}$} & \multirow{2}{*}{$P$-value } \\
\hline & & Mean & SD & Mean & SD & Mean & SD & \\
\hline \multirow{2}{*}{ S. mutans } & Base line $-2 \mathrm{~h}$ & $92.0^{\mathrm{B}}$ & 0.9 & $68.3^{\mathrm{C}}$ & 2.0 & $99.5^{\mathrm{A}}$ & 0.4 & $<0.001 *$ \\
\hline & Base line $-24 \mathrm{~h}$ & $89.3^{\text {в }}$ & 1.2 & $0.0^{\mathrm{C}}$ & 0.0 & $99.5^{\mathrm{A}}$ & 0.4 & $<0.001 *$ \\
\hline \multirow{2}{*}{ Lactobacilli } & Base line $-2 \mathrm{~h}$ & $0.0^{\mathrm{B}}$ & 0.0 & $0.0^{\mathrm{B}}$ & 0.0 & $99.6^{\mathrm{A}}$ & 0.2 & $<0.001 *$ \\
\hline & Base line $-24 \mathrm{~h}$ & $0.0^{\text {в }}$ & 0.0 & $0.0^{\text {в }}$ & 0.0 & $99.6^{\mathrm{A}}$ & 0.2 & $<0.001 *$ \\
\hline \multirow{2}{*}{ C. albicans } & Base line $-2 \mathrm{~h}$ & $87.5^{\text {в }}$ & 0.9 & $0.0^{\mathrm{C}}$ & 0.0 & $99.6^{\mathrm{A}}$ & 0.2 & $<0.001 *$ \\
\hline & Base line $-24 \mathrm{~h}$ & $87.3^{\text {в }}$ & 0.8 & $0.0^{\mathrm{C}}$ & 0.0 & $99.6^{\mathrm{A}}$ & 0.2 & $<0.001 *$ \\
\hline
\end{tabular}

*: Significant at $P \leq 0.05$

$A, B, C$ superscripts in the same row indicate statistically significantly difference between groups

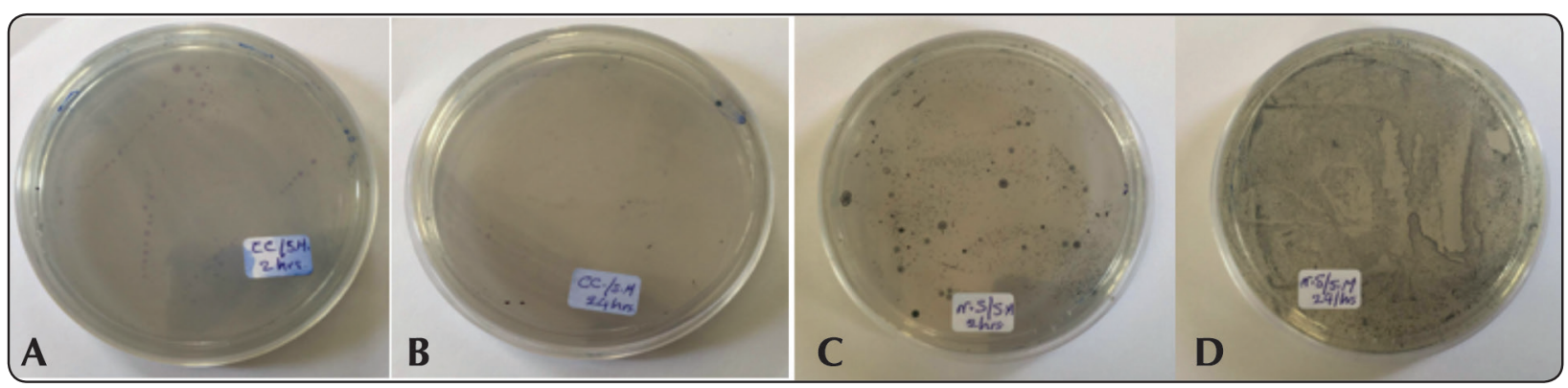

Fig. (2): Strepococcus mutans after 2 and 24 hours (A\&B with coconut oil, while B\&C with Nigella Sativa oil)

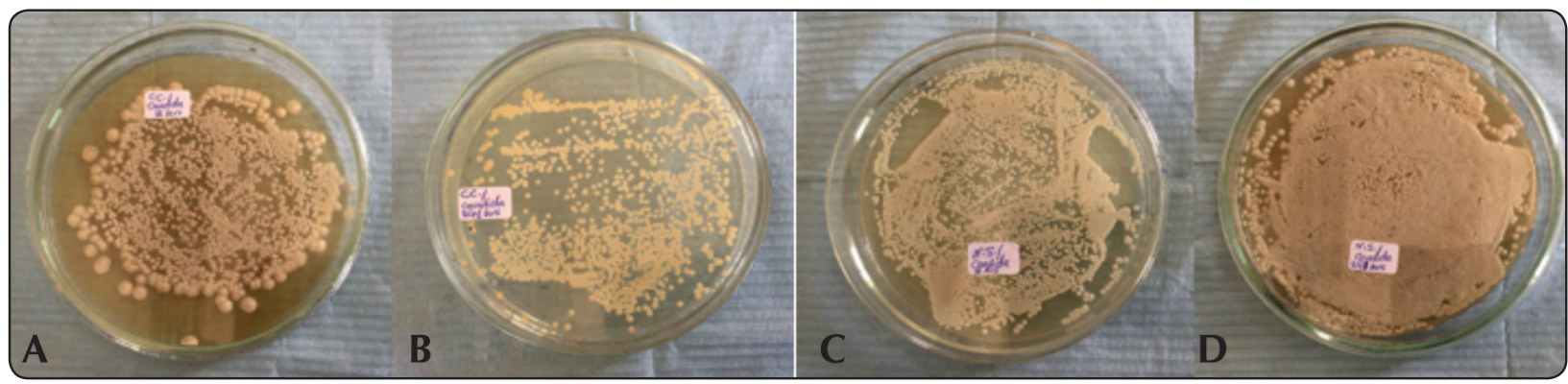

Fig. (3): Candida Albicans after 2 and 24 hours (A\&B with coconut oil, while C\&D with Nigella Sativa oil) 


\section{DISCUSSION}

Back to nature is one of the recent concepts utilized in the field of general as well as dental health. The use of medicinal plants has been started since human civilization. By searching for the use of herbal medicines, it was found to be increased greatly in the last three decades especially with increasing the resistance of human pathogenic microorganisms to traditional means of treatment ${ }^{(17)}$.

As dental caries is the most prevalent oral infectious disease affecting humans and it is considered the major reason of teeth loss, so this study was conducted to find an alternative way to reduce and inhibit the metabolic activity of cariogenic microorganisms (Streptococcus mutans, Lactobacilli and Candida albicans) ${ }^{(25)}$.

In this in vitro study, two types of nutritional oils (Coconut and Nigella sativa oils) were tested regarding their inhibitory effect on the previously mentioned cariogenic microorganisms, as well as to compare their effects as natural products with the commercially available $0.2 \%$ Chlorhexidine as gold standard to overcome its undesirable effects on the teeth and the oral structures ${ }^{(26)}$.

For this study to be conducted, the authors decided to evaluate the inhibitory effect of the tested oils using the inhibition zone method on agar plates. Unfortunately, neither of the tested oils showed any effect after proper incubation period. This problem could be attributed to high viscosity leading to poor difusibility of the tested oils, so another test was conducted depending on direct contact between tested oils and microorganisms and then counting the number of $\mathrm{CFU}^{(27)}$.

Among the results of this study, we can observe that coconut oil had a great inhibitory effect on Streptococcus mutans expressed as CFU after 2 and 24 hours observation period, with the greatest reduction after 2 hours, then its effect decreased by time. This result was supported by ${ }^{(28,29)}$ who attributed this inhibitory effect to the hydrophobic activity of the oil which may lead to destruction of lipid content of the bacterial cell membrane with disturbing the cellular structure that became more permeable with the result leakage of intracellular components, inhibition of energy production of the bacterial cell and finally cell death.

Although the exact mechanism of action of Coconut oil is still debatable and unclear, it was suggested that coconut oil is a medium chain fatty acid which contains $92 \%$ saturated acids, about $50 \%$ of them is Lauric acid ${ }^{(30)}$ with its metabolite monolurine (monoglyceride of Lauric acid). This in turns has an antimicrobial effect against various types of gram +ve and gram -ve microorganisms. These products were proved to protect against infection caused by bacteria, viruses, yeast and parasites ${ }^{(30-34)}$.

On the other hand, the results didn't show any effect of Coconut oil on Lactobacilli which was not supported by ${ }^{(5)}$ who confirmed a significant reduction of Lactobacilli in their clinical studies. In our opinion, this may be attributed to different used microbiological testing techniques and implementation methods.

As regard the yeast (Candida albicans) which are strong organism and can grow and multiply without any restrains, the results of this study showed that coconut oil had an excellent inhibitory effect on yeast with a significant reduction in the number of CFU after 2 and 24 hours. This result was strongly supported by ${ }^{(5,31)}$ who reported that Candida albicans showed a high sensitivity to Coconut oil due to the presence of antifungal components (Capric and Lauric acids) which are medium chain fatty acids that possess an antifungal activity (fungicidal). The mechanism by which these fatty acids can kill the organism is still unknown, but the electron microscopic studies showed that they can disrupt the cell membrane. 
Additionally, the results of this study showed a great inhibitory effect of Nigella sativa on Streptococcus mutans count after 2 hours. This finding agreed with (16) who reported that there was an inhibition zone of black seeds oil against Streptococcus mutans which may be attributed to the antimicrobial activity of the monohydroquinone (in the chemical composition of black seeds oil extract against gram +ve microorganisms). Also, this could be attributed to the presence of other volatile oils as Nigellone/ thymoquinone and thymol in the chemical composition of the cold pressed black seeds oil extract.

Another opinion was reported by ${ }^{(35,36)}$ who suggested that the presence of high content of protein in black seeds oil extract which were proved to be involved in the defense mechanism against the microorganisms especially a protein called Purindoline.

Although this great inhibitory effect of Nigella sativa against Streptococcus mutans after 2 hours, the result showed no inhibitory effect after 24 hours contact which means that Nigella sativa had its effect at the beginning of contact, but this effect decreases and disappears by time.

On contrary Nigella sativa oil showed no effect on Lactobacilli, neither after 2 hours nor after 24 hours. In our opinion this could be attributed to high resistance of these organisms to this natural oil.

The same result was obtained when evaluating the effect of Nigella sativa on Candida albicans, after 2 hours and after 24 hours contact period. This result was not supported by ${ }^{(1)}$ who reported that methanolic extract of Nigella sativa oil showed a strong antifungal effect followed by the chloroform extract of the oil. In this study, no effect was observed on Candida albicans this may be due to the use of cold pressed oil without adding any component, or due to the nature of the yeast which is highly resistant in general.

Although Chlorhexidine is our gold standard in this study and has been extensively used to aid in treatment of some oral conditions, it is highly discouraged because of its unpleasant taste and undesirable effects such as tooth discoloration ${ }^{(37)}$.

From the results of this study we can observe that our gold standard $(0.2 \%$ Chlorhexidine gluconate) has a strong inhibitory effect on all tested microorganisms after 2 and 24 hours contact period. The results showed a bactericidal effect and broad spectrum antimicrobial activity. This may be attributed to its ability to precipitate and coagulate the intracellular components of the organisms leading to cellular death ${ }^{(37)}$.

\section{CONCLUSIONS:}

Within the limitations of the current in vitro study, the following conclusions could be withdrawn:

1- Coconut oil has a great inhibitory effect on both Streptococcus mutans and Candida albicans with this effect extending by time.

2- Nigella sativa oil has an inhibitory effect on Streptococcus mutans over a short contact period, but this effect decreased and even vanished by time, but it has no effect on Candida albicans.

3- Although Coconut has better results than Nigella sativa, both oils showed no inhibitory effect on Lactobacilli.

4- Chlorhexidine (as a gold standard) showed the most superior results on all tested microorganisms.

\section{RECOMMENDATIONS}

1- Further researches are recommended to study the effect of these natural oils on the tested microorganisms.

2- The use of more advanced and extended microbiological techniques to be able to establish the use of the natural products instead Chlorhexidine.

3- In vivo studies are highly recommended especially for children to reduce the risk and effect of Early Childhood Caries. 


\section{REFERENCES}

1. Alm A: On dental caries and caries related factors in children and teenagers. Swed Dent J; 195: 7-63, 2008

2. Al-Malik MI, Rehbini YA: Prevalence of dental caries, severity, and pattern in age 6-7 years old children in a selected community in Saudi Arabia. J Contemp Dent Prac; 7(2): 046-054, 2006.

3. Marsh PD: Microbiological aspects of the chemical control of plaque and gingivitis. J Dent Res; 71: 1431-143, 1992.

4. Marchant S, Brailsford R, Ywomey AC, Roberts J, Beighton D: The predominant microflora of nursing caries lesions. Caries Res; 35(6): 397-402, 2001.

5. Jose M, Cyriac MB, Pai V, Varghese I, Shantaram M: Antimicrobial properties of cocos nucifers (Coconut) husk: An extrapolation to oral health. J Nat Scien, Biol and Medic; 5(2): 359-364, 2014.

6. Li Y, Tanner A: Effect of antimicrobial interventions on the oral microbiota associated with early childhood caries. Pediatr Dent; 37(3): 226-244 2015.

7. Suci PA, Tyler BJ: Action of Chlorhexidine against yeast and filamentous forms in an early stage Candida albicans biofilm. Antimicrob agents and Chemotherap; 46(11): 3522-3531, 2002.

8. Newman MG; Takei HH, Klokkvold P, Carranza FA: Carranza's Clinical Periodontol, 10 th ed; 9: 134-142, 2006.

9. Vahabi S, Najafi E, Alizadeh S: In vitro antimicrobial effects of some herbal essences against oral pathogens. J Medic Plants Res. 5(19): 4870-4878, 2011.

10. Groppo FC, Bergamaschi CC, Cogon K, Franz-Montana M, Motta RHL, Andrde ED: Use of phototherapy in dentistry: A review article. Phytother Res; 22: 993-998, 2008.

11. Ahmad A, Husain A, Mujeeb M, Khan SA, Najmi AK, Siddique NA, Damanhouri ZA, Anwar F: A review on therapeutic potential of Nigella sativa: A miracle herb. Asian Pacif J Trop Biomed; 3(5): 337-352, 2013.

12. Khare CP: Encyclopedia of Indian medicinal plants. NewYork: Springes-Verlag Berlin Heidelberg, 2004.

13. Ko"kdil G, Yilmaz H: Analysis of the fixed oils of the genus Nigella L. (Ranunculaceae) in Turkey. Biochem Systematics and Ecolo; 33: 1203-1209, 2005.

14. Aboul-Ela EI: Cytogenetic studies on Nigella sativa seeds extract and thymoquinone on mouse cells infected with schistosomiasis using karyotyping. Mutat Res; 516: 11-17, 2002.

15. Harzallah H, Kouidhi B, Flamini G, Bakhrouf A, Mahjoub T: Chemical composition, antimicrobial potential against cariogenic bacteria and cytotoxic activity of Tunisian Nigella sativa essential oil and thymoquinone. Food Chemistry; 129:1469-1474, 2011.

16. Abd-Awn B, Al-Dhaher Z, Al-Dafaai R. The effect of black seed oil extracts on mutans streptococci in comparison to chlorhexidine gluconate (in vitro): J of Baghdad College of Dentist; 24:126-131, 2012.

17. Mohammed NA: Effect of Nigella Sativa L extracts against streptococcus mutans and streptococcus mitis in vitro. $\mathrm{J}$ of Baghdad College of Dentist; 24:154-157, 2012.

18. Gasong BT, Hartani AW, Tjandrawinta RR: Antibacterial activity of Nigella sativa L.seed oil in water emulsion against dental cariogenic bacteria Inter J Pharmac Scien Res; 8 (7): 3155- 3161, 2017.

19. Debmandal M, Mandal S: Coconut (Cocus nucifera L:: Arecaceae): in helth promotion and disease prevention. Asian Pacific J Trop Medic; 4 (3):241- 247, 2001.

20. Dyyrit FM: Properties of Lauric acid and their significance in coconut oil. J Am Oil Chemists Soc; 92: 1-15, 2015.

21. Peedikayil FC, Remy V, John S, Chndru TP, Sreenivasan P, Bijapur GA: Comparison of antibacterial efficacy of cocnut oil and chlorhexidine on Streptococcus mutans: An in vivo study. J Int Soc Prev Comm Dentist; 6 (5): 447-452, 2016

22. Shino B, Peedikayil FC, Shyamala R, Jaiprakash R, Biapur GA, Kottayi S, Jose D: Comparison of antimicrobial activity of chlorhexidine, coconut oil, probiotics, and ketoconazole on candida albicans isolated in children wit early childhood caries: An in vitro study. Scientifica; doi: 10.1155/2016/7061587, 2016.

23. Petti S, Tarsitani G, D'Arca AS: A randomized clinical trial of the yoghurt on human salivary microflora. Arch. Oral Biol; 46: 705-712, 2001.

24. Rown R, Poxton R: Textbook of practical medical microbiology. $14^{\text {th }}$ edition, ch $48,845-8$ Centrifuges, colotimeters and bacterial count, 1996.

25. Alviano DS, Alviano CS: Plant extracts: Search for new alternatives to treat microbial diseases. Curr Pharm Biotechnol; 10:106-121, 2009. 
26. Jone CG: Chlorhexidine, Is it still a gold standard? J Periodontol 2000; 15: 55-62, 1997.

27. El-Sayed MA, MA, Abd El-Ghany IH, Eissa SA: Effect of Probiotic Bacteria and Bioyoghurt on Growth Inhibition of Salivary Mutans Streptococci, Lactobacilli and Candida: An In-vitro Study. Egypt Dent J; 54: 1681-1692, 2008.

28. Sikkem J, Debont AM, Poolman BM: Interaction of cyclic hydrocarbons with biological membranes. J Biol Chem; 269: 8022-8028, 1994.

29. Thaweboon S, Nakparksin J, Thaweboon B: Effect of oil pulling on oral microorganisms in biofilm models. Asia $\mathrm{J}$ Public Health; 2(3): 62-66, 2011.

30. Hierholzer JC, Kabara JJ: Invitro effect of monolaurin compounds on enveloped RNA and DNA viruses. J Food Safety; 4(1): 1-12, 1982.

31. Ogboulu DO, Oni AA, Oloko AP: Invitro antimicrobial properties of coconut oil on Candida species in Ibdan, Nigeria. J Med Food; 10: 384-387, 2007.
32. Pehowick DJ, Gomes AV, Branes JA: Fatty acid composition and possible health effects of coconut constituents. West Indian Med; 49: 128-133,2000.

33. Verallo-Rowell VM, Dillague KM, Syah-Tyundawan BS: Novel antibacterial and emollient effects of coconut and virgin olive oils in adult atopic dermatitis. Dermatitis;19: 308-315, 2008.

34. Jitjumroonchokchai P, Hirankerd K: Study on efficiency of antibiotic soap made from various kinds of plant oil. Agricult Sci J; 40: 221-224, 2009.

35. Morsi NM: Antimicrobial effect of crude extracts of Nigella sativa and multiple antibiotics resistant bacteria. Acta Microbiol Pol; 49(1): 63-74, 2000.

36. Hosseinzadeh H, Bazzar BSF, Haghi MM: Antimicrobial activity of total extracts and essential oil of Nigella sativa L. seeds in mice. Pharmacol; 2: 429-435, 2007.

37. McDonell G, Rusell AD: Antiseptic and disinfectants: Activity, action and resistance. Clin Microbiol Rev; 12: 147$149,1999$. 